\title{
Vision related daily life problems in patients waiting for a cataract extraction
}

\author{
Mats Lundström, Gunvor Fregell, Anita Sjöblom
}

\begin{abstract}
Problems in daily life activities caused by bad vision were studied in 150 patients with cataract before and 6 months after a cataract extraction. A relation was found between binocular visual acuity before surgery and the number of problems experienced $(p<0.001)$. After cataract extraction a reduction in problems was closely associated with an increase in visual acuity $(p<0.001)$ and also, in the patients' opinion, a better life situation $(\mathbf{p}<0.001)$. Six questions to be answered when considering surgery are given.

(Br F Ophthalmol 1994; 78: 608-611)
\end{abstract}

The development of a cataract with subsequent visual disabilities and adaptation of daily life activities is a gradual process with great individual variation. In many cases cataract extraction is performed eventually. The decision to operate in these cases is usually based on the existence of lens opacities, visual acuity, visual disturbances, and the patients' perceived visual disabilities. Other factors such as age, other eye diseases, etc also modify the timing of surgery. The time when the surgery is performed varies greatly between different individuals. The timing of surgery, however, may be important for the functional outcome. ${ }^{1}$ It is important, therefore, to clarify the grade of visual disabilities and perform the cataract extraction before important daily life activities have been abandoned.

According to some authors there is a bad correlation between visual acuity and perceived visual disabilities. ${ }^{2}$ It has also been pointed out that there may be a large variation in visual acuity results when different ophthalmologists examine the same patients. Recording the patients' perceived disabilities will give less variable results. ${ }^{3}$ Testing contrast sensitivity and glare may give a better correlation with perceived disabilities than testing visual acuity only. ${ }^{4}$

Various indices have been used to get valid and scientifically based measurements of patients' visual disabilities and thereby a better indication of the need for and timing of surgery. ${ }^{56}$ Too many questions and procedures may, however, be difficult to handle in daily practice. A few decisive routine questions about visual disabilities in cataract would therefore be helpful. When constructing such general questions one has to identify vision related daily life problems in patients with cataract. These problems must be frequent, weighted high, and be affected by a successful cataract extraction.?

\section{Aim of the study}

(1) To identify the most commonly perceived disabilities in daily life caused by bad vision in patients with cataract.

(2) To rank the perceived problems with regard to frequency and weight.

(3) To identify to what extent the perceived problems are affected by a successful cataract extraction.

(4) To outline a minimum number of decisive questions about visual disabilities in these patients.

\section{Patients}

Patients with senile or presenile cataract who were to undergo cataract extraction were included in the study if they met the following criteria:

a diagnosis of senile or presenile cataract in one or

both eyes

no other known eye diseases

able to consent

able to cooperate

consecutive cases

earlier cataract extraction in one eye.

The patient was excluded from the study if no surgery was performed.

A total of 150 patients were enrolled in the study but 11 were lost during follow up because of death or unwillingness to cooperate. Thus, the final study group comprised 139 cases. Sixty eight per cent of the patients were women. The mean age was $75 \cdot 6$ (range 45 to 100 ; median 77 ) years. Surgery in a second eye was performed in $29 \%$ of the cases.

About $30 \%$ of the patients were referred for surgery from ophthalmic medical practitioners and about $70 \%$ were originally referred to the ophthalmic outpatient department from general practioners or opticians.

\section{Methods}

Each patient underwent routine ocular examination before and after surgery including a 6 month postoperative control. Visual acuity was tested in the eye listed for surgery and in both eyes at best correction with a Monoyer-Granström letter chart.

All patients were interviewed by one of us (AS) before surgery. Thus, all patients were questioned in the same way. If necessary words could be explained or questions repeated. The questions were formulated in plain Swedish and proved easy to understand. The interview contained questions about problems caused by bad vision in 37 specific daily activities in eight main areas of daily life. These were mobility, housework, reading, TV, social life, hobbies and spare time activities, holiday and travelling, and ability to enjoy beautiful sights. The activities highlighted by the interview were either known from 
Table 1 Visual acuity and reading ability in the affected eye and in both eyes before surgery and 6 months after cataract extraction $(n=139)$

\begin{tabular}{lcc}
\hline & Before surgery & $\begin{array}{l}6 \text { months } \\
\text { after surgery }\end{array}$ \\
\hline $\begin{array}{l}\text { Visual acuity } \geqslant 0 \cdot 5: \\
\quad \text { Surgery eye }\end{array}$ & $18(13 \%)$ & $122(88 \%)$ \\
$\begin{array}{l}\text { Both eyes } \\
\text { Ability to read J1-J3: } \\
\quad \begin{array}{l}\text { Surgery eye } \\
\text { Both eyes }\end{array}\end{array}$ & $94(68 \%)$ & $131(94 \%)$ \\
\hline
\end{tabular}

Table 2 Number of patients who said they had one or several problems in the eight main daily activities before surgery (1) and 6 months following surgery $(2)(n=139)$

\begin{tabular}{llll}
\hline & \multicolumn{2}{l}{ Number of patients } & \\
\cline { 2 - 3 } Category & 1 & 2 & Reduction \\
\hline Mobility & 107 & 45 & 62 \\
Social life & 105 & 42 & 63 \\
Reading activities & 104 & 41 & 63 \\
Hobby/spare time & 90 & 29 & 61 \\
Housework & 81 & 21 & 60 \\
Enjoy sights & 80 & 20 & 60 \\
Watch TV & 80 & 19 & 61 \\
Holiday/travelling & 77 & 19 & 58 \\
\hline
\end{tabular}

other published reports as difficult to perform by patients with cataract and bad vision or were chosen from our own clinical experience. The patients were also asked about other problems they had within each main area of activity. In each question it was pointed out that only problems due to bad vision should be considered. The reason for using questions about problems instead of questions about ability to perform an activity was to minimise the influence of other diseases and handicaps. The reason for giving up an activity in the elderly is often multifactorial. Patients were also asked to grade problems into one of three categories: very big, big, or small. The weight of a problem was not calculated by the importance of a given activity, but by how difficult it was to perform that activity.

When the frequency of weighted problems was evaluated, no problem was given a value of 0 , a small problem 1 , a big problem 2 , and a very big problem 3. The interview also contained questions about the influence of visual disabilities on humour, family life, and general life situation. The interview was repeated 6 months after

Table 3 Number of persons describing problems caused by bad vision in 37 daily life activities before surgery (1) and 6 months after surgery (2) $(n=139)$

\begin{tabular}{|c|c|c|c|c|c|c|c|}
\hline & & \multicolumn{2}{|c|}{ Number } & & & \multicolumn{2}{|c|}{ Number } \\
\hline \multicolumn{2}{|c|}{ Activity } & $I$ & 2 & \multicolumn{2}{|c|}{ Activity } & 1 & 2 \\
\hline 1 & Recognising faces & 103 & 39 & 20 & Picking berries & 35 & 4 \\
\hline 2 & Reading books & 99 & 37 & 21 & Seeing flowers & 34 & 6 \\
\hline 3 & Walking on uneven ground & 94 & 37 & 22 & Carrying out repairs & 28 & 7 \\
\hline 4 & Reading papers & 88 & 38 & 23 & Making phone calls & 26 & 7 \\
\hline 5 & Reading TV text & 78 & 17 & 24 & Travelling & 24 & 2 \\
\hline 6 & Doing needlework & 72 & 26 & 25 & Going by bus and train & 24 & 8 \\
\hline 7 & Seeing kerbs & 69 & 25 & 26 & Gardening & 23 & 4 \\
\hline 8 & Walking in the woods & 66 & 16 & 27 & Cooking & 19 & 5 \\
\hline 9 & Shopping & 66 & 17 & 28 & Indoor mobility & 17 & 5 \\
\hline 10 & Seeing views & 59 & 16 & 29 & Club activities & 15 & 1 \\
\hline 11 & Being in traffic & 59 & 20 & 30 & Washing & 15 & 3 \\
\hline 12 & Climbing stairs & 56 & 27 & 31 & Going to restaurants & 14 & 2 \\
\hline 13 & Reading/writing letters & 48 & 10 & 32 & Visiting cinema/theatre & 13 & 3 \\
\hline 14 & Watching TV (picture) & 48 & 13 & 33 & Visiting friends & 11 & 0 \\
\hline 15 & Outdoor mobility & 48 & 15 & 34 & Being at sea/boating & 11 & 2 \\
\hline 16 & Seeing photos/pictures & 48 & 12 & 35 & Doing handicrafts & 10 & 0 \\
\hline 17 & Seeing facial expressions & 43 & 5 & 36 & Playing music & 3 & 3 \\
\hline 18 & Cleaning up & 41 & 6 & 37 & Doing sport & 1 & 0 \\
\hline 19 & Doing post office work & 39 & 13 & & & & \\
\hline
\end{tabular}

surgery by the same person (AS), in most cases by telephone. The questions were identical to those in the first interview.

\section{Results}

Visual acuity before surgery when the first interview was performed and 6 months after surgery when the second interview was performed is shown in Table 1. The numbers of patients with problems in the eight main categories of daily activity before and after surgery are shown in Table 2 and Table 3 gives the numbers of patients with problems before and after surgery in another 37 specific daily activities. Difficulties with other specific activities such as cycling, porcelain painting, collecting stamps, cutting, microfilming, hunting, attendance at church, doing crosswords, playing bingo, were mentioned.

Six patients before surgery and 64 patients after surgery said that they did not perceive problems in any of the specific daily life activities mentioned. Before surgery $32(23 \cdot 7 \%)$ patients thought their general quality of life was affected by their visual problems. After surgery 110 $(79 \cdot 1 \%)$ patients thought that their quality of life had changed: in four it was worse, in 59 $(42 \cdot 4 \%)$ it was better, and in $47(33.8 \%)$ much better.

SEX

Before surgery women noticed problems in 5.59 (mean value) main areas and men in 4.42 (mean value) main areas. The mean frequency of weighted specific problems was $22 \cdot 7$ for women and $18 \cdot 1$ for men.

After surgery the mean number of main problems was 1.89 in women and 1.29 in men. The mean number of weighted specific daily life problems was 5.8 in women and 3.7 in men. Thus the sex difference remained after surgery.

AGE

The mean number of perceived problems was different in different age groups both before and after surgery (Table 4). A regression analysis of the number of main problem areas before surgery shows that they diminished with age $(\mathrm{p}<0.05$; $p=0.0201)$. There is also a tendency for fewer perceived weighted problems with age before surgery, but this tendency is not statistically significant. After surgery there is a tendency to more perceived problems with age, but this tendency is not significant.

Table 4 The reduction of perceived problems in daily life activities in different agc groups after a cataract extraction. The pre-and postoperative values are shown in brackets. The effect is significantly reduced in higher age groups for both categories of problems (main problem area $p<0.01$; weighted problems in 37 specific daily life activities $p<0.05$ )

\begin{tabular}{lll}
\hline $\begin{array}{l}\text { Age } \\
\text { years })\end{array}$ & $\begin{array}{l}\text { Reduction of perceived } \\
\text { problem in } 8 \text { main areas }\end{array}$ & $\begin{array}{l}\text { Reduction of perceived } \\
\text { problems in 37 daily } \\
\text { life activities }\end{array}$ \\
\hline$\leqslant 70$ & $4 \cdot 8(6 \cdot 2-1 \cdot 4)$ & $22 \cdot 0(24 \cdot 9-2 \cdot 9)$ \\
$71-80$ & $3 \cdot 4(5 \cdot 0-1 \cdot 6)$ & $15 \cdot 8(21 \cdot 3-5 \cdot 5)$ \\
$>80$ & $2 \cdot 9(4 \cdot 8-1 \cdot 9)$ & $12 \cdot 4(18 \cdot 5-6 \cdot 1)$ \\
\hline
\end{tabular}


Table 5 Mean values of main problems and specific daily activity problems in patients with different best corrected binocular vision before surgery (1) and 6 months after surgery (2)

\begin{tabular}{|c|c|c|c|c|c|c|}
\hline \multirow{2}{*}{$\begin{array}{l}\text { Visual } \\
\text { acuity }\end{array}$} & \multicolumn{2}{|c|}{ Number of patients } & \multicolumn{2}{|c|}{$\begin{array}{l}\text { Main problems } \\
\text { (mean values) }\end{array}$} & \multicolumn{2}{|c|}{$\begin{array}{l}\text { Weighted specific problems } \\
\text { (mean values) }\end{array}$} \\
\hline & 1 & 2 & 1 & 2 & 1 & 2 \\
\hline $\begin{array}{l}\leqslant 0.3 \\
0 \cdot 4-0.6 \\
\geqslant 0.7\end{array}$ & $\begin{array}{l}33 \\
39 \\
62\end{array}$ & $\begin{array}{r}3 \\
23 \\
108\end{array}$ & $\begin{array}{l}6 \cdot 2 \\
4 \cdot 8 \\
4 \cdot 8\end{array}$ & $\begin{array}{l}5 \cdot 3 \\
2 \cdot 9 \\
1 \cdot 3\end{array}$ & $\begin{array}{l}32 \cdot 0 \\
19 \cdot 9 \\
15 \cdot 7\end{array}$ & $\begin{array}{r}28 \cdot 7 \\
8 \cdot 7 \\
3 \cdot 2\end{array}$ \\
\hline
\end{tabular}

Table 6 Correlation between number of perceived problems in the eight main areas of daily life activities and in 37 specific daily life activities and binocular visual acuity or patient opinion about change in general life situation caused by bad vision before surgery (1) and by improved vision 6 months after cataract extraction $(2)(n=139)$

\begin{tabular}{llllll}
\hline & \multicolumn{2}{l}{ Binocular visual acuity } & & \multicolumn{2}{c}{ Change in life situation } \\
\cline { 2 - 3 } \cline { 5 - 6 } Correlation & 1 & 2 & & 1 & 2 \\
\hline $\begin{array}{l}\text { Ranking problems in 8 main areas } \\
\text { of daily life activities }\end{array}$ & $-0.2232^{\star}$ & $-0.2464^{\star}$ & & $-0.4141^{\star \star}$ & $-0.4431^{\star \star}$ \\
$\begin{array}{l}\text { Ranking problems in 37 specific } \\
\text { daily life activities }\end{array}$ & $-0.2825^{\star \star}$ & $-0.2695^{\star}$ & & $-0.4703^{\star \star}$ & $-0.4305^{\star \star}$ \\
\hline
\end{tabular}

Spearman correlation coefficient ${ }^{\star}=\mathrm{p}<0 \cdot 01,{ }^{\star \star}=\mathrm{p}<0.001$.

\section{VISUAL ACUITY}

Table 5 shows the distribution of perceived problems in different levels of binocular visual acuity before and after surgery. The relation between binocular visual acuity and the number of main problem areas and the number of weighted daily life problems respectively has been studied using the Spearman correlation coefficient. Binocular visual acuity has been expressed in decibel values with equal steps between each acuity value. ${ }^{8}$ The correlation before and after surgery is shown in Table 6 . This table also includes the correlation between the number of problems and the patients' opinion of change in their general life situation caused by bad vision or by improved vision after surgery.

\section{LIVING CONDITIONS}

We found no correlation between living alone and number of perceived problems.

\section{Changes between the interviews}

There was a difference in number of perceived problems, visual acuity, and the judgment of change in general life situation between the two interviews. Is there any relation between these changes?

The relation between the patients' opinion about lesser problems in daily life activities after

Table 7 The patients' opinion about change in life situation caused by improved vision after a cataract extraction and mean number of changes in perceived problems in daily life activities. The relation between a change of life situation in a positive direction and a reduction of perceived problems is statistically significant for both problems in main areas of daily life $(p<0.001)$ and in 37 specific daily life activities $(p<0.001)$

\begin{tabular}{lll}
\hline & $\begin{array}{l}\text { Change of } \\
\text { perceived } \\
\text { problems in } 8\end{array}$ & $\begin{array}{l}\text { Change of } \\
\text { perceived problems } \\
\text { in 37 daily life } \\
\text { mactivities }\end{array}$ \\
\hline Change in life situation & -1.4 & $-7 \cdot 6$ \\
\hline Unchanged & -3.5 & -16.4 \\
Better & -5.0 & -22.0 \\
\hline
\end{tabular}

surgery and better general life situation is significant. That relation is shown in Table 7 .

The reduction of problems due to bad vision in daily life activities after surgery was significantly less in older than in younger people (see Table 4).

The relation between change in perceived problems from interview 1 to interview 2 and change in binocular visual acuity has been calculated using the Spearman correlation coefficient. In the main problem areas the figure is $-0 \cdot 3004$ $(\mathrm{p}<0.001)$ and for weighted problems in 37 specific daily activities the figure is -0.2953 $(\mathrm{p}<0.001)$. There is, evidently, a strong relation between the change in number of problems and the change in binocular visual acuity.

\section{Reduction of questions}

In a vision health quality test, however, it is not practical to ask about 37 different activities. Is it possible to get the same statistical result with fewer questions? To find out we chose six different activities for closer study. The activities are recognising faces, reading papers, walking on uneven ground, reading the text on TV, doing needlework, and shopping. These activities are characterised in our study by a high frequency of problems before surgery; surgery significantly decreased the number of patients with these problems (Table 8).

Those six activities were studied in the same way as the total number of activities. The correlation between the reduction of perceived problems in those six activities, change in best vision, and the patients' opinion of change in life situation after surgery is shown in Table 9.

\section{Discussion}

This study of problems in daily life activities in patients undergoing cataract extraction was meant to give a basis for more structured questions about perceived visual disabilities in cataract patients. The most frequent problems found in this study are in agreement with earlier studies and experience. In addition, however, we found that some problems in performing activities are weighted higher than others, and we also found that some rather rare activities were rated as very important based on personal preferences.

The number of problems varied greatly at each level of best visual acuity. There was, however, a significant relation between bad binocular visual acuity and a large number of problems. The same relation was found between a bad reading ability (Jaeger text) and a large number of problems.

The use of an interview in a study like this is based upon the assumption that the patients understand the questions, know the answers, and are honest when giving their answers. One of our inclusion criteria to the study was that the patient could understand the questions and give answers. In every question it was pointed out that only problems caused by bad vision should be considered.

Why did so many patients feel that they had problems 6 months after the surgery? This may be explained by several factors. Many patients had cataract in the other eye at that time $(n=82)$; some of the patients did not achieve good vision 
Table 8 Number of patients with problems before and after surgery in six of the most decisive activities.

\begin{tabular}{|c|c|c|c|c|}
\hline \multirow[b]{2}{*}{ Activity } & \multicolumn{2}{|c|}{$\begin{array}{l}\text { Number of patients with } \\
\text { problems }\end{array}$} & \multirow{2}{*}{$\begin{array}{l}\text { Reduction in } \\
\text { problems }(\%)\end{array}$} & \multirow{2}{*}{$\begin{array}{l}\text { Weight in } \\
\text { interview } 1 \\
(\%)^{\star}\end{array}$} \\
\hline & Interview 1 & Interview 2 & & \\
\hline \multicolumn{5}{|l|}{ Mobility: } \\
\hline Walking on uneven ground & 94 & 37 & 60 & 60 \\
\hline \multicolumn{5}{|l|}{ Reading: } \\
\hline Reading papers & 88 & 36 & 59 & 72 \\
\hline \multicolumn{5}{|l|}{ Social life: } \\
\hline Recognising faces & 103 & 39 & 62 & 67 \\
\hline Shopping & 66 & 17 & 74 & 62 \\
\hline \multicolumn{5}{|l|}{ Spare time: } \\
\hline Reading TV text & 78 & 17 & 78 & 60 \\
\hline Doing needlework & 72 & 26 & 64 & 72 \\
\hline
\end{tabular}

*Weight is expressed as the percentage who ranked their problems as high or very high in the first interview.

Table 9 Correlation between pre/post surgical difference of perceived problems in the six most decisive daily life activities and pre/post surgical difference in binocular visual acuity or patients' opinion about change in general life situation caused by improved vision after the cataract extraction $(n=139)$

\begin{tabular}{lll}
\hline Correlation & $\begin{array}{l}\text { Difference in binocular } \\
\text { visual acuity }\end{array}$ & $\begin{array}{l}\text { Change in } \\
\text { life situation }\end{array}$ \\
\hline Ranking difference in problems in 6 activities of daily life & $-0.3733^{\star \star}$ & $-0.4553^{\star \star}$ \\
\hline
\end{tabular}

Spearman correlation coefficient. ${ }^{\star \star}=\mathrm{p}<0.001$.

after surgery; furthermore, the visual acuity in the non-operated eye was below 0.5 at 6 months after surgery in $56(41 \cdot 2 \%)$ patients.

Another finding was that patients with one level of binocular visual acuity before surgery felt they had more problems than patients with the same level of binocular visual acuity after surgery. This may be explained by the relief from visual disturbances such as glare in the postsurgery group.

There was a slight difference in perceived problems between the sexes both before and after surgery. This may be due to the nature of the questions. We found an obvious decrease in perceived problems with increasing age. This may be due to the gradual decrease in activities in daily life that characterises old people. Another factor may be an impairment in cognitive functions with age, resulting in a poor way of expressing oneself.

The decrease in problems after surgery was significantly less in older patients. This may be because of less improvement in binocular visual acuity after surgery than in young patients and perhaps the influence of other diseases and handicaps. Thus, in our study older patients felt they had fewer problems before surgery than young patients when asked about 37 specific daily activities, and the reduction of problems was less after surgery than in young patients. This pattern was the same in both mobility activities and reading activities in contrast with the findings of Brenner. ${ }^{9}$ Another possible reason for the reduced influence of surgery in older patients may be the difficulty in taking up activities after surgery if the period of inactivity has been too long. ${ }^{1}$

Cataract extraction reduced the number of patients who felt they had problems caused by bad vision by between 42 and $45 \%$ in each of the eight main areas of daily activities. If specific daily activities are considered the number of patients with problems caused by bad vision was reduced still more (Table 3 ). It is difficult to compare our figures with other studies because of differences in methods and selecton of patients. It has earlier been reported that $44 \%$ of cataract patients said it was easier to walk outdoors after the surgery. ${ }^{10}$ In the same report the number of patients who recognised faces increased from $26 \%$ before surgery to $64 \%$ after surgery. The selection of patients was different from our study, however. It can be concluded that in our study we found a close relation between better vision after a cataract extraction and a reduction of perceived problems in daily life activities caused by bad vision. We also found a close relation between the patients' opinion about their better life situation after surgery and the reduction in problems. This strong correlation was also found if the number of activities was reduced from 37 to the six most decisive activities. The choice of these activities is also supported by earlier reports in literature. ${ }^{11} 1314$

These six daily life activities (Table 8) are important to the elderly and are frequently performed. The ability to perform them depends on either good visual acuity or good contrast sensitivity for lower or intermediate spatial frequencies. ${ }^{12} 15$ These visual functions deteriorate when cataract is present. Therefore, based on our study and other published reports, we recommend, as a quick test of visual disabilities in daily life activities in patients with cataract, specific questions about these six activities. We also recommend an open question about special interests or hobbies.

This study was supported by grants from the Council for Health Care Research in South Sweden (HSF) and Lund University.

1 Bernth-Petersen $P$, Ehlers N. Cataract extraction in the 'nineties'. Acta Ophthalmol (Copenh) 1983; 61: 392-6.

2 Bernth-Pedersen P. Outcome of cataract surgery I: a prospective, observational study. Acta Ophthalmol (Copenh) 1982; 60: $235-42$

3 Gibson RA, Sanderson HF. Observer variation in ophthalmology. Br f Ophthalmol 1980; 64: 457-60.

4 Elliott DB, Sanderson K, Conkey A. The reliability of the Pelli-Robson contrast sensitivity chart. Ophthalmic Physiol Opt 1990; 10: 21-4

5 Bernth-Petersen P. Visual functioning in cataract patients. Methods of measuring and results. Acta Ophthalmol (Copenh) 1981; 59: 198-205.

6 Mangione CM, Russell SP, Seddon MJ, et al. Development of the 'Activities of daily vision scale'. A measure of visual functional status. Medical Care 1992; 30: 1111-26.

7 Guyatt GH, Bombardier C, Tugwell PX. Measuring diseasespecific quality of life in clinical trials. Can Med Assoc 7 1986; 134: 889-95.

8 Lundh BL, Aringer S. Three dB-scales for the standardized visuogram. Vision Res 1984; 24: 889-90.

9 Brenner MH. Cataract extraction with intraocular lens implantation: the assessment of patient benefit through quality of life. Final report to: The American Society of Cataract and Refractive Surgery. The Johns Hopkins University, 1990.

10 Spri. Cataract extractions. Costs and benefit of an intraocular lens. Stockholm: Spri, 1988 (Spri report 261:2)(in Swedish).

11 Häkkinen L. Vision in the elderly and its use in the social environment. Scand F Soc Med 1984 (Suppl 35).

12 Tieger T, Ganz L. Recognition of faces in the presence of twodimensional sinusoidal masks. Percept Psychophys 1979; 26: 163-7.

13 Agner E, Hein HO. Sygdom og sundhed blandt 80-årige. En epidemiologisk undersögelse. (Summary in English) Nord

14 Rubin AM, Rubin RB. Older persons' TV viewing patterns and motivations. Commun Res 1982; 9: 287-313.

15 Pastalan LA. Environmental design and adaptation to the visual environment of the elderly. In: Sekuler $R$, Kline D, Dismukes K, eds. Aging and human visual function. New York: Alan R Liss, 1982: 323-33. 